Disclosure of Interest: None declared

DOI: 10.1136/annrheumdis-2017-eular.6473

\section{FRI0321 CIRCULATING IL-6 AND OTHER METABOLIC BIOMARKERS COMPARING EFFECTS OF MODIFIED-RELEASE PREDNISONE (MR) AND IMMEDIATE-RELEASE PREDNISOLONE (IR) IN NEW GCA}

E. Miler ${ }^{1}$, S. Mapplebeck ${ }^{1}$, C. Mackerness ${ }^{1}$, L. Wilson ${ }^{1}$, T. Aung ${ }^{1}$, D. Gayford ${ }^{1}$, J.P. Schofield ${ }^{2}$, B. Dasgupta ${ }^{1} .{ }^{1}$ Southend University Hospital NHS Foundation Trust, Westcliff-on-Sea; ${ }^{2}$ Napp Pharmaceuticals Limited, Cambridge Science Park, Milton Road, United Kingdom

Background: GCA may be an interleukin-6 (IL-6) driven disease and IL-6 blockade is emerging as an exciting therapy of IL-6. ${ }^{1}$ We measured serial IL-6 levels in new patients with GCA treated in an RCT of modified-release prednisone (MR) versus immediate-release prednisolone (IR) used in a tapering regimen conforming to BSR quidelines. , $^{2,3}$

Methods: Patients $(n=12)$ were randomised into two treatment arms (7 MR, 5 IR) and followed up over 26 weeks. IL- 6 samples were collected at 9am at weeks 4 , 10, 18 and 26 and were measured using Beckman Coulter IL-6 immunoassay, validated in a controlled study according to ACB criteria. We also measured bone markers (CTX, P1NP, vitamin D), HbA1c, cortisol, ACTH and PTH.

Results: Significantly higher overall mean IL-6 levels were seen in the IR arm $(n=5)$ compared to MR $(n=7)$ [unpaired two-tailed Student's $t$ test]. IL-6 levels in both arms were lowest between weeks $4-10$ and continued to decrease in the IR arm to week 26, whereas lower but constant levels were seen in the MR arm (Figure)

Mean CTX concentration was significantly higher at week $4(\mathrm{M}=0.29, \mathrm{SE}=0.04)$ compared to Week 26 ( $M=0.13, S E=0.02) p=0.002$. No significant difference was seen between treatment arms.

Patients on MR had complete suppression of ACTH compared to IR $(p<0.05)$ without a significant difference between groups in 9 am cortisol levels $(p=0.3412)$. No significant differences were seen in levels of vitamin D, calcium, PTH, ESR, CRP, or HbA1c.

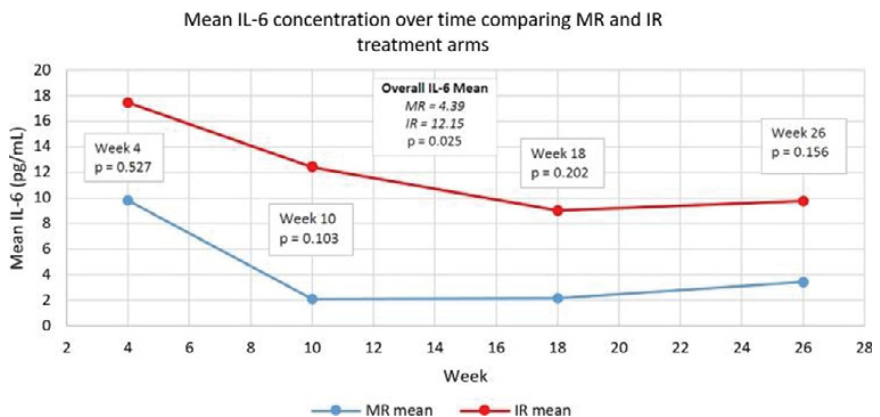

Conclusions: Our study suggests that elevated levels of II-6 are better suppressed by MR prednisone therapy compared to IR prednisolone in new GCA. Bone resorption marker CTX was significantly reduced in both treatment arms. ACTH suppression with MR prednisone may reflect a greater impact on the HPA axis although cortisol levels were not affected.

Our findings suggest that MR prednisone may warrant further clinical trial investigation in GCA.

\section{References:}

[1] Dasgupta, B. and Panayi, G.S., 1990. Interleukin-6 in serum of patients with polymyalgia rheumatica and giant cell arteritis. British journal of rheumatology, 29(6), pp. 456-458.

[2] Spies, C.M., Straub, R.H., Cutolo, M. and Buttgereit, F., 2014. Circadian rhythms in rheumatology-a glucocorticoid perspective. Arthritis research \& therapy, 16 Suppl 2, pp. S3.

[3] Dasgupta, B., Borg, F.A., Hassan, N., Alexander, L., Barraclough, K., Bourke, B., Fulcher, J., Hollywood, J., Hutchings, A., James, P., Kyle, V., Nott, J., Power, M., Samanta, A. and BSR and BHPR Standards, Guidelines and Audit Working Group, 2010. BSR and BHPR guidelines for the management of giant cell arteritis. Rheumatology (Oxford, England), 49(8), pp. 1594-1597.

Acknowledgements: Napp Pharmaceuticals Limited, Beckman Coulter, Gabriel Labinjo for technical support.

Disclosure of Interest: E. Miler: None declared, S. Mapplebeck: None declared, C. Mackerness: None declared, L. Wilson: None declared, T. Aung: None declared, D. Gayford: None declared, J. P. Schofield Grant/research support from: Napp Pharmaceuticals Limited and Napp distributes prednisone MR in U.K.

(Lodotra), B. Dasgupta: None declared

DOI: 10.1136/annrheumdis-2017-eular.3550

\section{FRI0322 ASSESSMENT OF DAMAGE AND PROGNOSIS IN PATIENTS WITH ADULT IGA VASCULITIS: RETROSPECTIVE MULTICENTERED COHORT STUDY}

F. Alibaz-Oner ${ }^{1}$, A. Omma ${ }^{2}$, A. Sarı ${ }^{3}$, O. Karadag ${ }^{3}$, D. Uskudar Cansu ${ }^{4}$, C. Bes ${ }^{5}$, F. Yildiz ${ }^{6}$, M.F. Oksuz ${ }^{7}$, S. Yilmaz ${ }^{8}$, A. Balkarli ${ }^{9}$, S. Ureyen ${ }^{10}$, H. Direskeneli ${ }^{1}{ }^{1}$ Rheumatology, Marmara University, School of Medicine, Istanbul; ${ }^{2}$ Rheumatology, Ankara Numune Education and Research Hospital;

${ }^{3}$ Rheumatology, Hacettepe University, School of Medicine, Ankara;

${ }^{4}$ Rheumatology, Osmangazi University, School of Medicine, Eskisehir;

${ }^{5}$ Rheumatology, Bakırkoy Sadi Konuk Education and Research Hospital, Istanbul; ${ }^{6}$ Rheumatology, Van Education and Research Hospital, Van;

${ }^{7}$ Rheumatology, Uludag University, School of Medicine, Bursa; ${ }^{8}$ Rheumatology, Selcuk University, School of Medicine, Konya; ${ }^{9}$ Rheumatology, Antalya Education and Research Hospital, Antalya; ${ }^{10}$ Rheumatology, Sakarya Education and Research Hospital, Sakarya, Turkey

Background: IgA Vasculitis is a leukocytoclastic vasculitis involving small vessels with depositions of immune complexes containing IgA. There is limited data for the prognosis of adult IgA Vasculitis, with also no damage assessment.

Objectives: We aimed to evaluate the clinical characteristics, treatment, outcome and damage of patients with adult IgA Vasculitis.

Methods: We assembled a retrospective cohort of patients with adult IgA Vasculitis, from tertiary Rheumatology Centers in Turkey. All data were abstracted from medical records. Birmingham Vasculitis Activity Score (BVAS),prognostic Five Factor Score (FFS) and vasculitis damage index (VDI) were calculated.

Results: The study included 52 (male/female:40/12) patients with adult IgA Vasculitis. The mean age was $42.2 \pm 17$ years. Infection history within 6 weeks before presentation was present in $22(42.3 \%)$ patients (18 upper respiratory tract, 3 gastrointestinal and 1 urinary tract). Cutaneous manifestations were the most common clinical manifestations (Table 1). All patients were treated with oral glucocorticoids (GC).As additional immunosuppressive agents, azathiopirine was given to $21(40.4 \%)$ and pulse cyclophosphamide to $11(21.2 \%)$ patients. Twenty-eight patients (53.9\%) had follow-up of 28.6 months. Five (17.8\%) patients relapsed during follow-up. While 3 relapses were major, 2 of them were minor relapses. At the last visit, disease status was evaluated as active or treatment failure by the treating physician in $6(21.4 \%)$ patients. Mortality was $3.6 \%(n=1)$ during follow-up, due to pneumonia. The mean VDI score was 0.6 in the last visit. Nine (32.1\%) patients had at least one damage item at the end of follow-up period.

Table 1. Clinical characteristics of patients with adult IgA Vasculitis

\begin{tabular}{lc}
\hline & Adult IgA Vasculitis $(\mathrm{n}=52)$ \\
\hline Laboratory parameters & \\
Erythrocyte Sedimentation Rate $\left(\mathrm{mm} / \mathrm{hour}^{*}\right.$ & $32.7 \pm 22$ \\
C-reactive protein $\left(\mathrm{mg} / \mathrm{l}^{\dagger}\right.$ & $25.2(1-94.9)$ \\
Proteinuria $(>300 \mathrm{mg} / 24$ hours) & $28(53.9 \%)$ \\
Creatinine $(\mathrm{mg} / \mathrm{dl})^{\star}$ & $0.9 \pm 0.4$ \\
Clinical Manifestations, $\mathrm{n} / 52(\%)$ & \\
Fever & $7(13.5 \%)$ \\
Weight loss & $14(26.9 \%)$ \\
Myalgia/Weakness/Leg tenderness & $24(46.2 \%)$ \\
Arthritis and/or arthralgia & $46(88.5 \%)$ \\
Neurologic manifestations & $1(1.9 \%)$ \\
Testicular pain or tenderness & $3(5.8 \%)$ \\
Recent onset or severe hypertension & $2(3.8 \%)$ \\
Cutaneous Manifestations & $48(92.3 \%)$ \\
Gastrointestinal manifestations & $39(75 \%)$ \\
FFS $=0$ & $29(55.8 \%)$ \\
FFS $=1$ & $15(28.8 \%)$ \\
FFS $\geq 2$ & $8(15.4 \%)$ \\
BVAS score at diagnosis ${ }^{*}$ & $4.1 \pm 1.7$ \\
\hline
\end{tabular}

FFS: Five Factor Score, BVAS: Birmingham Vasculitis Activity score. ${ }^{*}$ Mean $\pm \mathrm{SD}$; ${ }^{\dagger}$ Median (Minimum-maximum.)

Conclusions: Our results showed that approximately one fifth of patients with adult IgA Vasculitis had relapses during follow-up. At the end of follow-up, one third of patients had at least one damage item. Although, $45 \%$ of patients had $F F S \geq 1$, the mortality rate was observed to be low in the present study.

Disclosure of Interest: None declared

DOI: 10.1136/annrheumdis-2017-eular.3865

\section{FRI0323 COMPARISON OF BIOPSY PROVEN GIANT CELL ARTERITIS IN NORTH AMERICA AND SOUTHERN EUROPE: A POPULATION-BASED STUDY}

F. Muratore $^{1}$, C.S. Crowson ${ }^{2}$, L. Boiardi ${ }^{1}$, M.J. Koster ${ }^{2}$, G. Restuccia ${ }^{1}$, T.A. Kermani ${ }^{3}$, E.L. Matteson ${ }^{2}$, C. Salvarani ${ }^{1}$, K.J. Warrington ${ }^{2} .{ }^{1}$ Rheumatology Unit, Arcispedale Santa Maria Nuova IRCCS, Reggio Emilia, Italy; ${ }^{2}$ Division of Rheumatology, Mayo Clinic, Rochester, MN; ${ }^{3}$ Department of Medicine, David Geffen School of Medicine, University of California, Los Angeles, United States

Objectives: To compare clinical characteristics, treatment, long-term follow-up and prognosis of two population-based cohorts of patients with biopsy-proven giant cell arteritis (GCA) from Olmsted County, Minnesota, USA (Olmsted cohort) and the Reggio Emilia area, Northern Italy (Reggio cohort).

Methods: All patients residing in Olmsted County and the Reggio Emilia area 